\title{
Weak binding affinity of human 4EHP for mRNA cap analogs
}

\author{
JOANNA ZUBEREK, ${ }^{1,4}$ DOROTA KUBACKA, ${ }^{1,4}$ AGNIESZKA JABLONOWSKA, ${ }^{2}$ JACEK JEMIELITY, ${ }^{1}$ \\ JANUSZ STEPINSKI, ${ }^{1}$ NAHUM SONENBERG, ${ }^{3}$ and EDWARD DARZYNKIEWICZ ${ }^{1}$ \\ ${ }^{1}$ Department of Biophysics, Institute of Experimental Physics, Warsaw University, 02-089 Warsaw, Poland \\ ${ }^{2}$ Institute of Biochemistry and Biophysics, Polish Academy of Sciences, 02-106 Warsaw, Poland \\ ${ }^{3}$ Department of Biochemistry and McGill Cancer Center, McGill University, Montreal, Quebec, H3G 1Y6, Canada
}

\begin{abstract}
Ribosome recruitment to the majority of eukaryotic mRNAs is facilitated by the interaction of the cap binding protein, elF4E, with the mRNA $5^{\prime}$ cap structure. elF4E stimulates translation through its interaction with a scaffolding protein, elF4G, which helps to recruit the ribosome. Metazoans also contain a homolog of elF4E, termed 4EHP, which binds the cap structure, but not elF4G, and thus cannot stimulate translation, but it instead inhibits the translation of only one known, and possibly subset mRNAs. To understand why 4EHP does not inhibit general translation, we studied the binding affinity of 4EHP for cap analogs using two methods: fluorescence titration and stopped-flow measurements. We show that 4EHP binds cap analogs $\mathrm{m}^{7} \mathrm{GpppG}$ and $\mathrm{m}^{7} \mathrm{GTP}$ with 30 and 100 lower affinity than eIF4E. Thus, 4EHP cannot compete with elF4E for binding to the cap structure of most mRNAs.
\end{abstract}

Keywords: 4EHP; eIF4E isoforms; mRNA 5' cap; binding affinity; stopped-flow

\section{INTRODUCTION}

All nuclear transcribed eukaryotic mRNAs possess a common structure called a "cap" at their 5' end, which consists of 7-methylguanosine bound by a $5^{\prime}-5^{\prime}$-triphosphate bridge to the first transcribed nucleotide. The cap structure is important for stabilizing the mRNA (Furuichi and Shatkin 2000), facilitating the splicing of pre-mRNAs (Konarska et al. 1984), promoting mRNA transport to cytoplasm (Izaurralde et al. 1992), and facilitating the binding of ribosomes to the mRNA (Mathews et al. 2000; Pestova et al. 2007). Cap-dependent translation begins with recognition of the cap structure by eIF4E, which forms a heterotrimeric complex with eIF4A, which is thought to melt the mRNA $5^{\prime}$ secondary structure and the scaffolding protein eIF4G that binds other factors to recruit the ribosome (Mathews et al. 2000). The interaction of eIF4E with eIF4G is controlled by a group of proteins generally known as eIF4E inhibitory proteins, which share a common

\footnotetext{
${ }^{4}$ These authors contributed equally to this work.

Reprint requests: Edward Darzynkiewicz, Department of Biophysics, Institute of Experimental Physics, Warsaw University, Zwirki i Wigury 93, 02-089 Warsaw, Poland; e-mail: edek@biogeo.uw.edu.pl; fax: +48 225540771.

Article published online ahead of print. Article and publication date are at http://www.rnajournal.org/cgi/doi/10.1261/rna.453107.
}

eIF4E-binding site with eIF4G. Whereas some 4EBPs repress translation of a large number of mRNAs by associating only with eIF4E (Raught et al. 2000), others, more recently discovered, such as Cup or Maskin, inhibit translation of specific mRNAs by binding simultaneously to eIF4E and additional proteins that interact with sequence elements in the mRNA 3' UTR (Wilhelm et al. 2003; Cao and Richter 2002).

Crystallographic, NMR, and biophysical studies determined the amino acids in eIF4E that are of primary importance for cap structure recognition (Marcotrigiano et al. 1997; Matsuo et al. 1997; Niedzwiecka et al. 2002; Tomoo et al. 2003). The structural basis for the specificity of the eIF4E-cap interaction is the sandwiching of the 7-methylguanine base via $\pi-\pi$ stacking interactions between tryptophan indol rings (Trp56 and Trp102). This interaction is stabilized by van der Waals contacts of the $\mathrm{m}^{7} \mathrm{G}$ with Trp166 and hydrogen bonds with Glu103. The phosphate chain of the cap structure forms direct or water-mediated hydrogen bonds with NH groups of Trp102 and Trp166 as well as with side chains of lysine and arginine residues (Arg112, Arg157, and Lys162).

eIF4E homologs have been identified in most organisms (except for Saccharomyces cervisiae). In mammals, there are three members of the eIF4E family: eIF4E (eIF4E-1), 4EHP 
(eIF4E-2), and eIF4E-3 (Rom et al. 1998; Joshi et al. 2004). Based on sequence alignments, h4EHP, together with nCBP from plants (Ruud et al. 1998), IF4E-4 from Caenorbiditis elegans and d4EHP (deIF4E-8) from Drosophila melanogaster are members of the eIF4E-2 class (Joshi et al. 2005). Members of this class possess mainly Tyr/Phe in the position corresponding to Trp43 and Tyr in the position of Trp56 of human eIF4E (Joshi et al. 2005). In h4EHP both of these positions are occupied by tyrosine (Fig. 1). Mouse and human 4EHP binds to $\mathrm{m}^{7}$ GTP-Sepharose but does not interact with eIF4G (Rom et al. 1998; Joshi et al. 2004) and cannot rescue the lethality of eIF4E gene deletion in yeast (Joshi et al. 2004). Recently, the Drosophila 4EHP has been reported to be a translation repressor that is required for the asymmetric distribution of caudal protein in the egg, which is essential for the appropriate development of the embryo (Cho et al. 2005). d4EHP blocks translation by binding to the $5^{\prime}$ cap structure of Caudal mRNA and to the regulatory protein Bicoid, which interacts with $3^{\prime}$ UTR of the caudal mRNA (Cho et al. 2005).

Here we present data on the binding affinities of cap analogs for human 4EHP versus human eIF4E using the fluorescence titration method and stopped-flow technique.

\section{RESULTS AND DISCUSSION}

\section{Proteins preparation}

All proteins were expressed in Escherichia coli in inclusion bodies, refolded by one-step dialysis, and purified using ion-exchange chromatography to avoid any contact with cap analogs (Niedzwiecka et al. 2002). Analysis of cell extracts and proteins after dialysis showed limited proteolysis of the $\mathrm{N}$ terminus. However, the application of ion-exchange column resulted in homogeneous full-length proteins (>95\%; Fig. 2). The amount of proper refolded protein, obtained from fluorescence titrations by fitting concentration of the "active" protein as a free parameter of the equilibrium equation, was about 70\%-85\% (Niedzwiecka et al. 2002).

\section{Different binding affinities of 4EHP and eIF4E for cap analogs}

The interaction between cap analogs and eIF4E results in quenching of intrinsic Trp fluorescence (Fig. 3A). 4EHP possesses six out of the eight conserved tryptophan residues of eIF4E and an additional tryptophan in the $\mathrm{C}$ terminus. Trp43 and Trp56 of eIF4E are replaced in 4EHP by tyrosines (Rom et al. 1998; Joshi et al. 2004). These differences result in slightly lower fluorescence intensities for equimolar protein solutions of 4EHP versus eIF4E. However, the emission spectra of both proteins are very similar (data not shown), suggesting no significant structural differences between the proteins as a result of the changes in the environment of Trp residues.

To determine the accurate association constants $\left(K_{\mathrm{as}}\right)$ for the complexes of $4 \mathrm{EHP}$ with a series of mono- and dinucleotide cap analogs, we applied the time-synchronized fluorescence titration method (Niedzwiecka et al. 2002) and the stopped-flow technique with an emission detector (Dlugosz et al. 2002). The $K_{\mathrm{as}}$ values obtained from fluorescence titration are shown in Table 1 , and the corresponding Gibbs free energy of binding $\left(\Delta G^{\circ}\right)$ are graphically presented in Figure $3 \mathrm{~B}$. The kinetic parameters for the association reaction protein-cap analog are shown in Table 2. As a control, $K_{\text {as }}$ for complexes of human eIF4E with all tested cap analogs were determined. It is striking that 4EHP binds all cap analogs significantly weaker than eIF4E. However, the differences among binding affinities depend on the nature of the cap analog. The association constant for 4EHP with $\mathrm{m}^{7} \mathrm{GTP}$ is about 100 -fold lower compared to that for eIF4E (Fig. 3A), whereas the dinucleotide triphosphate cap analogs $\left(\mathrm{m}^{7} \mathrm{GpppG}\right.$, $\mathrm{m}^{7} \mathrm{GpppA}$, and $\mathrm{m}^{7} \mathrm{GpppC}$ ) are bound by $4 \mathrm{EHP}$ about 30 -fold weaker. These data were also confirmed by stoppedflow measurements (Table 2). The results are in good agreement with the observations that human and Drosophila 4EHP bind $\mathrm{m}^{7} \mathrm{GTP}-$ Sepharose less efficiently than their eIF4E counterparts 


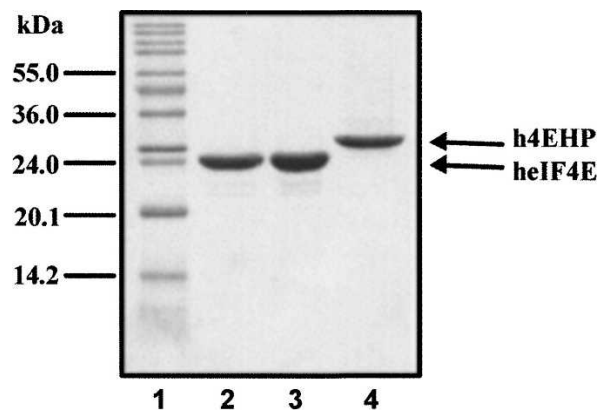

FIGURE 2. Purified on ion-exchange column proteins visualized on a Comassie-stained 15\% SDS-PAGE gel. Lane 1, protein marker weight standards (Sigma); lane 2, human eIF4E; lane 3, human eIF4EW56Y; and lane 4, human 4EHP.

(Tee et al. 2004; Cho et al. 2005). However, the differences of two orders of magnitude in binding affinities for the cap structure between the two proteins are striking, particularly because 4EHP, compared to eIF4E, possesses only three substitutions in the cap-binding slot: two conservative and one nonconservative (Fig. 1).

\section{Replacement of Trp56 by Tyr in eIF4E moderately stimulates cap binding affinity}

A mutant of human eIF4E possessing a leucine substitution of Trp56 fails to bind $\mathrm{m}^{7} \mathrm{GTP}-$ Sepharose (Morino et al. 1996). However, substitution of the corresponding tryptophan by phenylalanine in yeast eIF4E reduces eIF4E's binding to the cap structure by $50 \%$ only (Altmann et al. 1988). To elucidate the contribution of the 4EHP tyrosine residue (corresponding to Trp56 in eIF4E) to the weak binding affinity of 4EHP for the cap, we generated a mutant of eIF4E possessing tyrosine instead of tryptophan in position 56. Surprisingly, this mutant exhibits a slightly enhanced ( $\sim 1.5$-fold) binding to the cap structure (Table 1$)$. The $K_{\text {as }}$ for the complex of mutated eIF4E with $\mathrm{m}^{7} \mathrm{GTP}$ is $109.7 \pm 5.0 \mu \mathrm{M}^{-1}$, whereas for wild type eIF4E is $68.41 \pm$ $5.09 \mu \mathrm{M}^{-1}$. The increase of $K_{\mathrm{as}}$ for eIF4EW56Y is very similar for all tested cap analogs and does not depend on the number of phosphate groups. These results show that in eIF4E two tryptophans as well as tryptophan and tyrosine residues can sandwich 7 -methylguanine through the $\pi-\pi$ stacking interaction with similar efficiency. The recognition mode of the cap structure by the sandwich stacking of the $\mathrm{m}^{7} \mathrm{G}$ moiety via two aromatic rings of amino acids is exercised by other, eIF4E-unrelated, mRNA $5^{\prime}$ cap binding proteins. The vaccinia virus mRNA-cap-dependent $2^{\prime}-O$ methyltransferase, VP39, contains a tyrosine and a phenylalanine (Tyr22 and Phe180) (Hu et al. 1999) and the conserved nuclear cap binding protein, CBC20, contains two tyrosines (Tyr20 and Tyr43) (Mazza et al. 2002). The crystallographic structures of cap binding proteins supported by theoretical studies showed that the almost perfect alignment of the aromatic rings, an interplanar distance of 3.1-3.6 $\AA$, a substantial area of overlap in stacking rings, and the positive charge of $\mathrm{m}^{7} \mathrm{G}$ all contribute to the strong interaction between the $\pi$-electrons of stacked rings (Quiocho et al. 2000; Fechter and Brownlee 2005). The VP39, which possesses phenylalanine in the stacking mode, had the lowest binding affinity $\left(K_{\mathrm{as}} \sim 0.1 \mu \mathrm{M}^{-1}\right)$, and its replacement by tryptophan or tyrosine enhances binding. On the other hand, substitution of phenylalanine for Tyr22 cannot rescue the stacking interaction ( $\mathrm{Hu}$ et al. 1999; Hsu et al. 2000). The CBC20, in which two tyrosines are involved in stacking, exhibits binding affinity for $\mathrm{m}^{7} \mathrm{GTP}$ similar to eIF4E: $K_{\mathrm{as}}=29.7 \pm 2.3 \mu \mathrm{M}^{-1}$ for CBC (Worch et al. 2005) and $K_{\mathrm{as}}=33.28 \pm 1.04 \mu \mathrm{M}^{-1}$ for mouse eIF4E in buffer containing $200 \mathrm{mM} \mathrm{KCl}$ (Zuberek et al. 2004). The ring system of tyrosine is more $\pi$-electron rich than that of phenylalanine due to the electron-donating character of phenolic oxygen, which engenders a stronger stacking interaction between tyrosine and the positively charged $m^{7} G$ base. Thus, all these data suggest that the presence of Tyr78 instead of tryptophan cannot be the major reason for the 100-fold weaker binding of cap analogs to 4EHP than to its eIF4E counterpart. In human eIF4E Trp56 is located in loop S1-S2 between two $\beta$ sheets (Tomoo et al. 2003). This region in 4EHP contains five additional amino acids (Fig. 1), which can increase the flexibility of this loop. As a consequence, it may prevent the correct parallel alignment of the aromatic ring of Tyr78 and its substantial overlap with the $\mathrm{m}^{7} \mathrm{G}$ moiety essential for an efficient stacking interaction, which is adopted in the eIF4EW56Y mutant.

Recently, the cap binding affinities of four Leishmania eIF4E isoforms were determined (Yoffe et al. 2006). They all possess binding affinities for $\mathrm{m}^{7} \mathrm{GTP}$ similar to h4EHP. However, in LeishIF4E-1 two tryptophan residues and in LeishIF4E-4 one tyrosine and one tryptophan are involved in the stacking interaction. LeishIF4E-4 binds $\mathrm{m}^{7} \mathrm{GTP}$ even approximately fourfold stronger than LeishIF4E-1, which is in agreement with our results for the eIF4EW56Y mutant. These data suggest that not only is the type of aromatic amino acid (Tyr or Trp) engaged in the stacking interaction important for stabilizing the complex of the eIF4E-cap, but other structural elements also are important. However, homology modeling of either Leishmania isoforms (Yoffe et al. 2006) or h4EHP (Rom et al. 1998) did not predict significant differences in the three-dimensional structure compared to eIF4E.

\section{Effect of the negative charge of cap analogs on their affinity for 4EHP}

It has been shown previously that electrostatic interactions play a crucial role in the recognition of the cap structure by eIF4E (Niedzwiecka et al. 2002; Zuberek et al. 2004). The extension of the phosphate chain in cap analogs results in systematic, marked enhancement of the binding affinity for 

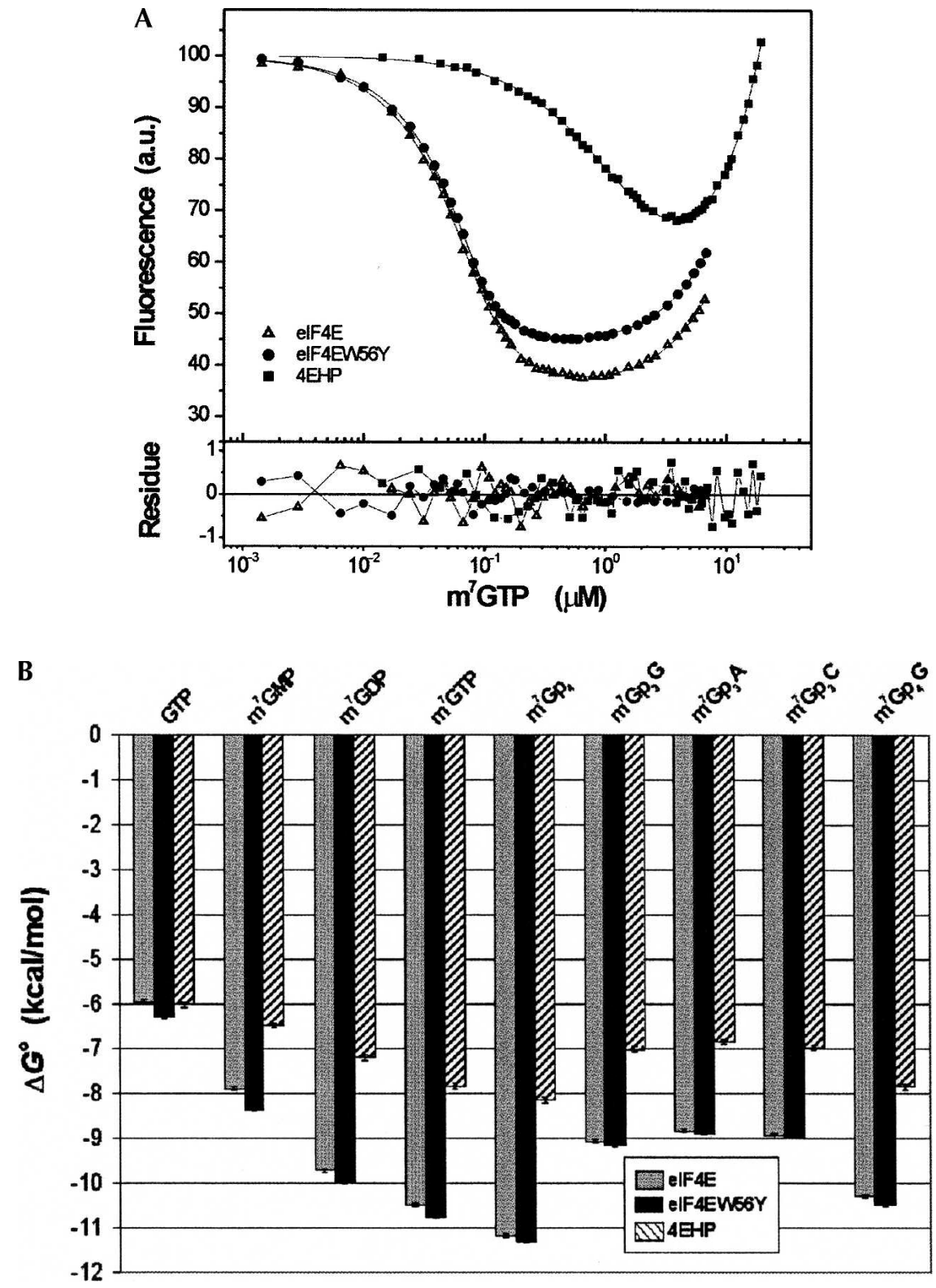

FIGURE 3. (A) Fluorescence titration curves for binding $\mathrm{m}^{7} \mathrm{GTP}$ to human eIF4E $(\Delta)$, its eIF4EW56Y mutant $(\bullet)$, human 4EHP ( $\bullet$ ), and fitting residuals. Titrations were carried out in $50 \mathrm{mM}$ HEPES/KOH (pH 7.2), $0.5 \mathrm{mM}$ EDTA, and $1 \mathrm{mM}$ DTT adjusting to $\mathrm{I}=150 \mathrm{mM}$ by $\mathrm{KCl}$ at $20^{\circ} \mathrm{C}$. Protein fluorescence, presented as relative value, was excited at $280 \mathrm{~nm}$ and observed at $337 \mathrm{~nm}$. The observed increasing fluorescence signal at a higher concentration of $\mathrm{m}^{7} \mathrm{GTP}$ originates from free-cap analog emission. (B) Graphical comparison of Gibbs free energy of binding $\left(\Delta G^{\circ}\right)$ for association of cap analogs with human eIF4E, its mutant, and human $4 \mathrm{EHP}$, calculated from obtained association constants $\left(K_{\mathrm{as}}\right)$.

eIF4E. 4EHP carries only two substitutions, with reference to positive charged amino acid in the cap binding slot of eIF4E (Fig. 1). A hydrophobic isoleucine substitutes for Lys162, which forms a direct hydrogen bond with an oxygen atom of the $\beta$-phosphate group (Tomoo et al. 2003). In addition, a lysine replaces Arg112, which in eIF4E interacts with the $\alpha$-phosphate group by a water-mediated hydrogen bond (Marcotrigiano et al. 1997; Tomoo et al.
2003). To establish the possible effect of substitutions on cap binding (especially the lack of a lysine residue), we analyzed the Gibbs free energy of binding in relation to the number of phosphate groups within the cap analogs (Fig. 3B). The addition of the $\beta$-phosphate group to the cap analog $\left(\mathrm{m}^{7} \mathrm{GMP} \rightarrow \mathrm{m}^{7} \mathrm{GDP}\right)$ gives a change in binding free energy of about $-0.7 \mathrm{kcal} / \mathrm{mol}$ for $4 \mathrm{EHP}$ and about $-1.8 \mathrm{kcal} / \mathrm{mol}$ for eIF4E. The difference between proteins of about $1.1 \mathrm{kcal} / \mathrm{mol}$ in the energetic cost $\left(\Delta \Delta G^{\mathrm{o}}\right)$ corresponds to one hydrogen bond. For both proteins the addition of a third $(\gamma)$ phosphate group $\left(\mathrm{m}^{7} \mathrm{GDP} \rightarrow \mathrm{m}^{7} \mathrm{GTP}\right)$ causes a comparable change of binding free energy (4EHP of about $-0.65 \mathrm{kcal} / \mathrm{mol}$; eIF4E of about $-0.8 \mathrm{kcal} / \mathrm{mol}$ ). This suggests that the lack of the lysine residue in $4 \mathrm{EHP}$ is partially responsible for the $\sim 100$-fold decrease in its binding affinity for $\mathrm{m}^{7} \mathrm{GDP}$ and $\mathrm{m}^{7} \mathrm{GTP}$ compared to eIF4E, whereas for $\mathrm{m}^{7} \mathrm{GMP}$ it is only 10 -fold. The weaker binding of $\mathrm{m}^{7} \mathrm{GMP}$ by $4 \mathrm{EHP}$ presumably results from the replacement of arginine by lysine with a shorter side chain, thus preventing the formation of a water-mediated hydrogen bond. The twofold increase in the association constant for $\mathrm{m}^{7} \mathrm{Gp}_{4}\left(K_{\mathrm{as}}=\right.$ $\left.1.20 \pm 0.04 \mu \mathrm{M}^{-1}\right)$ in comparison with $\mathrm{m}^{7} \operatorname{GTP}\left(K_{\mathrm{as}}=0.70 \pm 0.04 \mu \mathrm{M}^{-1}\right)$ suggests that the $\delta$-phosphate of the cap analog in contrast to eIF4E (threefold increase of $K_{\mathrm{as}}$ ) does not interact directly with the protein by forming hydrogen bonds.

\section{CONCLUSIONS}

Earlier studies suggested that h4EHP and d4EHP bind a cap structure weaker than eIF4E based on qualitative measurements using $\mathrm{m}^{7} \mathrm{GTP}-$ Sepharose (Tee et al. 2004; Cho et al. 2005). Here we used quantitative measurements to show that 4EHP binds to the cap structure with a very low affinity (30-100fold lower than eIF4E). The weak binding of 4EHP to the cap prevents it from competing with eIF4E for association with the mRNA cap and to inhibit translation. Translational inhibition of caudal mRNA occurs only when 4EHP simultaneously binds the cap and Bicoid. The association of d4EHP with Bicoid might enhance its affinity for the cap. 
TABLE 1. Equilibrium association constants $\left(K_{\mathrm{as}}\right)$ for the complexes of cap analogs with the human elF4E, elF4EW56Y mutant, and human 4EHP obtained from analysis of steady-state fluorescence titrations at $20^{\circ} \mathrm{C}$

\begin{tabular}{lccc}
\hline Cap analog & $\begin{array}{c}\text { elF4E } \\
K_{\text {as }}\left(\mu \mathrm{M}^{-1}\right)\end{array}$ & $\begin{array}{c}\text { elF4EW56Y } \\
K_{\text {as }}\left(\mu \mathrm{M}^{-1}\right)\end{array}$ & $\begin{array}{c}4 \text { EHP } \\
K_{\text {as }}\left(\mu \mathrm{M}^{-1}\right)\end{array}$ \\
\hline $\mathrm{m}^{7} \mathrm{GMP}$ & $0.78 \pm 0.04$ & $1.79 \pm 0.04$ & $0.07 \pm 0.01$ \\
$\mathrm{~m}^{7} \mathrm{GDP}$ & $17.76 \pm 0.34$ & $29.5 \pm 0.6$ & $0.23 \pm 0.03$ \\
$\mathrm{~m}^{7} \mathrm{GTP}$ & $68.41 \pm 5.09$ & $109.7 \pm 5.0$ & $0.70 \pm 0.04$ \\
$\mathrm{~m}^{7} \mathrm{Gp} 4$ & $221.5 \pm 12.9$ & $272.6 \pm 10.6$ & $1.20 \pm 0.04$ \\
$\mathrm{~m}^{7} \mathrm{GpppG}$ & $5.94 \pm 0.39$ & $7.00 \pm 0.12$ & $0.17 \pm 0.01$ \\
$\mathrm{~m}^{7,2^{\prime} \mathrm{GpppG}}$ & $6.13 \pm 0.34$ & $7.42 \pm 0.16$ & $0.12 \pm 0.01$ \\
$\mathrm{~m}^{7} \mathrm{GpppA}$ & $3.97 \pm 0.21$ & $4.33 \pm 0.08$ & $0.13 \pm 0.01$ \\
$\mathrm{~m}^{7} \mathrm{GpppC}$ & $4.76 \pm 0.19$ & $5.09 \pm 0.14$ & $0.16 \pm 0.02$ \\
$\mathrm{~m}^{7} \mathrm{GppppG}$ & $47.88 \pm 2.12$ & $69.4 \pm 2.3$ & $0.72 \pm 0.02$ \\
$\mathrm{GTP}$ & $0.027 \pm 0.001$ & $0.051 \pm 0.002$ & $0.031 \pm 0.002$ \\
Total quenching & $\sim 65 \%$ & $\sim 57 \%$ & $\sim 57 \%$ \\
\hline
\end{tabular}

A similar mechanism of translational inhibition by h4EHP may occur by binding to as yet unidentified proteins.

\section{MATERIALS AND METHODS}

\section{Synthesis of cap analogs}

Syntheses of mono- and dinucleotide cap analogs were performed as described previously (Darzynkiewicz et al. 1985, 1990; Jemielity et al. 2003; Zuberek et al. 2004). The cap analog concentrations were determined spectrophotometrically (Cai et al. 1999).

\section{Cloning and mutagenesis}

The cDNA of human 4EHP, amplified from the pCDNA3HA_4EHP vector by PCR, was subcloned into the expression vector pET30a (Novagen) in NdeI-BamHI sites.

The QuikChange PCR-based site-directed mutagenesis kit (Stratagene) was used to obtain the point-mutations replacement of Trp56 by tyrosine in human eIF4E. As an initial template the cDNA for eIF4E in a pET11d vector (Novagen) was used and sitedirected mutagenesis was performed exactly according to the instructions provided by Stratagene. The presence of the mutation was confirmed by automatic DNA sequencing.

\section{Protein expression and purification}

For expression of the human eIF4E, an eIF4EW56Y mutant and 4EHP appropriate plasmids were transformed into E. coli
BL21(DE3) cells. Bacteria were grown in LB medium to $\mathrm{OD}_{600 \mathrm{~nm}}$ of 0.8 , and induced for $3 \mathrm{~h}$ at $37^{\circ} \mathrm{C}$ by adding $0.5 \mathrm{mM}$ isopropyl-1-thio- $\beta$-D-galactopyranoside (IPTG). Cells were harvested, resuspended in lysis buffer (20 mM HEPES/KOH [pH 7.5], 100 $\mathrm{mM} \mathrm{KCl}, 1 \mathrm{mM}$ EDTA, $2 \mathrm{mM}$ DTT, and $10 \%$ glycerol) and disrupted by sonication. After centrifugation of the lysate $(30,000 \mathrm{~g}$ for $30 \mathrm{~min}$ ) the supernatant was removed and the pellet was washed three times with wash buffer (20 mM HEPES/KOH [pH 7.2], $1 \mathrm{M}$ guanidine hydrochloride, $2 \mathrm{mM}$ DTT, and $10 \%$ glycerol). The inclusion bodies were dissolved in $50 \mathrm{mM}$ HEPES/KOH ( $\mathrm{pH} 7.2$ ), $6 \mathrm{M}$ guanidine hydrochloride, $10 \%$ glycerol, and $2 \mathrm{mM}$ DTT, and cell debris was removed by centrifugation $(43,000 \mathrm{~g}$ for $30 \mathrm{~min})$. The protein (diluted to a concentration lower than $0.1 \mathrm{mg} / \mathrm{mL}$ ) was refolded by one-step dialysis against $50 \mathrm{mM}$ HEPES/KOH (pH 7.2), $100 \mathrm{mM} \mathrm{KCl,} 1.0 \mathrm{mM}$ EDTA, and $2 \mathrm{mM}$ DTT, and purified by ion exchange chromatography on a HiTrap MonoSP column (Amersham Bioscience). The purified proteins were analyzed by SDS-PAGE and their concentrations were determined by absorption, assuming the following: $\varepsilon_{280}=53,400$ $\mathrm{M}^{-1} \mathrm{~cm}^{-1}$ for eIF4E, $\varepsilon_{280}=49,200 \mathrm{M}^{-1} \mathrm{~cm}^{-1}$ for eIF4EW56Y, and $\varepsilon_{280}=47,600 \mathrm{M}^{-1} \mathrm{~cm}^{-1}$ for $4 \mathrm{EHP}$ (calculated from amino acid composition using an algorithm on the ExPASy Server).

\section{Fluorescence binding titration}

Fluorescence titration measurements were carried out on an LS-50B or LS-55 spectrofluorometer (Perkin-Elmer), in $50 \mathrm{mM}$ HEPES/KOH ( $\mathrm{pH} 7.2$ ) and $0.5 \mathrm{mM}$ EDTA $1 \mathrm{mM}$ DTT, adjusting to an ionic strength of $150 \mathrm{mM}$ by $\mathrm{KCl}$ at $20.0 \pm 0.2^{\circ} \mathrm{C}$. Aliquots of $1 \mu \mathrm{L}$ increasing concentrations of cap analog solutions were added to $1.4 \mathrm{~mL}$ of 0.1 or $0.2 \mu \mathrm{M}$ protein solutions. Fluorescence intensities (excitation at $280 \mathrm{~nm}$ or $295 \mathrm{~nm}$ with a $2.5-\mathrm{nm}$ bandwidth and detection at $337 \mathrm{~nm}$ or $345 \mathrm{~nm}$ with a 4-nm bandwidth and a 290-nm cutoff filter) were corrected taking into account sample dilution and the inner filter effect. Equilibrium association constants $\left(K_{\mathrm{as}}\right)$ were determined by fitting the theoretical dependence of the fluorescence intensity on the total concentration of the cap analog to the experimental data points according to the equation described previously (Niedzwiecka et al. 2002). The concentration of protein was fitted as a free parameter of the equilibrium equation showing the amount of "active" protein. The final $K_{\text {as }}$ was calculated as a weighted average of 3-10 independent titrations, with the weights taken as the reciprocals of the numerical standard deviations

TABLE 2. Rate constants for association $\left(k_{+1}\right)$ and dissociation $\left(k_{-1}\right)$ of human elF4E and 4EHP with cap analogs obtained from fitting one-step model to the kinetic traces registered during stopped-flow experiments at $20^{\circ} \mathrm{C}$

\begin{tabular}{|c|c|c|c|c|c|c|}
\hline \multirow[b]{2}{*}{ Cap analog } & \multicolumn{3}{|c|}{ elF4E } & \multicolumn{3}{|c|}{ 4EHP } \\
\hline & $k_{+1}\left(\mu \mathrm{M}^{-1} \sec ^{-1}\right)$ & $k_{-1}\left(\sec ^{-1}\right)$ & $K_{\mathrm{as}}\left(\mu \mathrm{M}^{-1}\right)$ & $k_{+1}\left(\mu \mathrm{M}^{-1} \sec ^{-1}\right)$ & $k_{-1}\left(\sec ^{-1}\right)$ & $K_{\mathrm{as}}\left(\mu \mathrm{M}^{-1}\right)$ \\
\hline $\mathrm{m}^{7} \mathrm{GTP}$ & $690.9 \pm 7.9$ & $10.2 \pm 0.2$ & $67.7 \pm 1.8$ & $77.7 \pm 13.9$ & $105.1 \pm 3.4$ & $0.73 \pm 0.13$ \\
\hline $\mathrm{m}^{7} \mathrm{GpppG}$ & $163.1 \pm 2.7$ & $35.3 \pm 0.4$ & $4.6 \pm 0.1$ & $35.9 \pm 25.1$ & $154.0 \pm 7.2$ & $0.23 \pm 0.16$ \\
\hline
\end{tabular}


squared. Numerical nonlinear least-squares regression analysis was performed using ORGIN 6.0 (Microcal Software).

The Gibbs free energy of binding was calculated from the $K_{\text {as }}$ value according to the standard equation $\Delta G^{\circ}=-R T \ln K_{\mathrm{as}}$.

\section{Stopped-flow measurements and analysis of kinetics transients}

Kinetic measurements of interaction eIF4E and 4EHP proteins with $\mathrm{m}^{7} \mathrm{GTP}$ and $\mathrm{m}^{7} \mathrm{GpppG}$ were run on a SX.18MV stopped-flow reaction analyzer (Applied Photophysics) using fluorescence detection. The protein emission was excited at $290 \mathrm{~nm}$ (with a $0.5 \mathrm{~mm}$ slit) and its fluorescence was monitored after passage through a 320-nm cutoff filter. The path lengths in the stopped flow cell were $2 \mathrm{~mm}$ for absorption and $10 \mathrm{~mm}$ for emission. The reaction was initiated by mixing an equal volume of protein solution $(1 \mu \mathrm{M})$ with the cap analog $(0.5-8 \mu \mathrm{M}$ for eIF4E and 0.5-20 $\mu \mathrm{M}$ for 4EHP). The measurements were performed in $50 \mathrm{mM}$ HEPES/KOH ( $\mathrm{pH}$ 7.2), $0.5 \mathrm{mM}$ EDTA adjusted to an ionic strength of $150 \mathrm{mM}$ by $\mathrm{KCl}$ at $20.0 \pm 0.1^{\circ} \mathrm{C}$. The fluorescence changes were monitored up to a $200-\mathrm{msec}$ recording of 1000 data points using the oversampling option of the instrument. The kinetic traces for each concentration of the cap analog are an average of 14 independent runs.

The obtained kinetics traces were subjected to nonlinear leastsquares regression assuming a one-step model for the protein-cap analog association:

$$
\mathrm{P}+\mathrm{L} \underset{k_{-1}}{\stackrel{k_{+1}}{\rightleftharpoons}} \mathrm{PL}
$$

described by differential equations for rates of changes of concentration of molecular species

$$
\begin{aligned}
\frac{\mathrm{d}[\mathrm{P}]}{\mathrm{d} t} & =\frac{\mathrm{d}[\mathrm{L}]}{\mathrm{d} t}=-k_{+1}[\mathrm{P}][\mathrm{L}]+k_{-1}[\mathrm{PL}] \\
\frac{\mathrm{d}[\mathrm{PL}]}{\mathrm{d} t} & =k_{+1}[\mathrm{P}][\mathrm{L}]-k_{-1}[\mathrm{PL}]
\end{aligned}
$$

and its specific contributions to the monitored fluorescence signal

$$
F=[\mathrm{P}] \cdot f_{\mathrm{P}}+[\mathrm{PL}] \cdot f_{\mathrm{PL}}+[\mathrm{L}] \cdot f_{\mathrm{L}}
$$

where $k_{+1}$ and $k_{-1}$ are association and dissociation rate constants, respectively; $[\mathrm{P}],[\mathrm{L}]$, and $[\mathrm{PL}]$ are concentrations, and $f_{\mathrm{P},} f_{\mathrm{L}}$, and $f_{\mathrm{PL}}$, are molar fluorescence of free protein, free ligand, and complex. Numerical analysis was performed using the DynaFit program (BioKin) created by Peter Kuzmic (Kuzmic 1996).

\section{ACKNOWLEDGMENTS}

We thank Dr. Jan M. Antosiewicz (Warsaw University) for making the SX.18MV stopped-flow reaction analyzer available to us. This work was supported by Howard Hughes Medical Institute Grant No. 55005604 to E.D., Polish Ministry of Science and Higher Education Grant No. 2P04A 00628 to E.D., and the Canadian Institute of Health Research to N.S.

Received December 30, 2006; accepted February 6, 2007.

\section{REFERENCES}

Altmann, M., Edery, I., Trachsel, H., and Sonenberg, N. 1988. Sitedirected mutagenesis of the tryptophan residues in yeast eukaryotic initiation factor 4E. Effects on cap binding activity. J. Biol. Chem. 263: 17229-17232.

Cai, A.L., Jankowska-Anyszka, M., Centers, A., Chlebicka, L., Stepinski, J., Stolarski, R., Darzynkiewicz, E., and Rhoads, R.E. 1999. Quantitative assessment of mRNA cap analogues as inhibitors of in vitro translation. Biochemistry 38: 8538-8547.

Cao, Q. and Richter, J.D. 2002. Dissolution of the maskin-eIF4E complex by cytoplasmic polyadenylation and poly(A)-binding protein controls cyclin B1 mRNA translation and oocyte maturation. EMBO J. 21: 3852-3862.

Cho, P.F., Poulin, F., Cho-Park, Y.A., Cho-Park, I.B., Chicoine, J.D., Lasko, P., and Sonenberg, N. 2005. A new paradigm for translational control: Inhibition via $5^{\prime}-3^{\prime}$ mRNA tethering by Bicoid and the eIF4E cognate 4EHP. Cell 121: 411-423.

Darzynkiewicz, E., Ekiel, I., Tahara, S.M., Seliger, L.S., and Shatkin, A.J. 1985. Chemical synthesis and characterization of 7-methylguanosine cap analogs. Biochemistry 24: 1701-1707.

Darzynkiewicz, E., Stepinski, J., Tahara, S.M., Stolarski, R., Ekiel, I., Haber, D., Neuvonen, K., Lehikoinen, P., Labadi, I., and Lonnberg, H. 1990. Synthesis, conformation and hydrolytic stability of $\mathrm{P}^{1}, \mathrm{P}^{3}$-dinucleotide triphosphate related to mRNA $5^{\prime}$-cap, and comparative kinetic studies on their nucleoside and nucleotide monophosphate analogs. Nucleosides Nucleotides 9: 599-618.

Dlugosz, M., Bojarska, E., and Antosiewicz, J.M. 2002. A procedure for analysis of stopped-flow transients for protein-ligand association. J. Biochem. Biophys. Methods 51: 179-193.

Fechter, P. and Brownlee, G.G. 2005. Recognition of mRNA cap structure by viral and cellular proteins. J. Gen. Virol. 86: 1239-1249.

Furuichi, Y. and Shatkin, A.J. 2000. Viral and cellular mRNA capping: Past and prospects. Adv. Virus Res. 55: 135-184.

Hsu, P.C., Hodel, M.R., Thomas, J.W., Taylor, L.J., Hagedorn, C.H., and Hodel, A.E. 2000. Structural requirements for the specific recognition of an $\mathrm{m} 7 \mathrm{G}$ mRNA cap. Biochemistry 39: 1373013736.

Hu, G., Gershon, P.D., Hodel, A.E., and Quiocho, F.A. 1999. mRNA cap recognition: Dominant role of enhanced stacking interactions between methylated bases and protein aromatic side chains. Proc. Natl. Acad. Sci. 96: 7149-7154.

Izaurralde, E., Stepinski, J., Darzynkiewicz, E., and Mattaj, I.W. 1992. A cap binding protein that may mediate nuclear export of RNA polymerase II-transcribed RNAs. J. Cell Biol. 118: 1287-1295.

Jemielity, J., Fowler, T., Zuberek, J., Stepinski, J., Lewdorowicz, M., Niedzwiecka, A., Stolarski, R., Darzynkiewicz, E., and Rhoads, R.E. 2003. Novel "anti-reverse" cap analogs with superior transnational properties. RNA 9: 1108-1122.

Joshi, B., Cameron, A., and Jagus, R. 2004. Characterization of mammalian eIF4E-family members. Eur. J. Biochem. 271: 21892203.

Joshi, B., Lee, K., Maeder, D.L., and Jagus, R. 2005. Phylogenetic analysis of eIF4E-family members. BMC Evol. Biol. 5: 48.

Konarska, M.M., Padgett, R.A., and Sharp, P.A. 1984. Recognition of cap structure in splicing in vitro of mRNA precursors. Cell 38: 731-736.

Kuzmic, P. 1996. Program DYNAFIT for the analysis of enzyme kinetic data: Application to HIV proteinase. Anal. Biochem. 237: 260-273.

Marcotrigiano, J., Gingras, A.C., Sonenberg, N., and Burley, S.K. 1997. Cocrystal structure of the messenger RNA $5^{\prime}$ cap-binding protein (eIF4E) bound to 7-methyl-GDP. Cell 89: 951-961.

Mathews, M.B., Sonenberg, N., and Hershey, J.W.B. 2000. Origins and principles of translation control. In Translational control of gene expression (eds. N. Sonenberg et al.), pp. 1-32. Cold Spring Laboratory Press, Cold Spring Harbor, NY.

Matsuo, H., Li, H., McGuire, A.M., Fletcher, C.M., Gingras, A.C., Sonenberg, N., and Wagner, G. 1997. Structure of translation 
factor eIF4E bound to m7GDP and interaction with 4E-binding protein. Nat. Struct. Biol. 4: 717-724.

Mazza, C., Segref, A., Mattaj, I.W., and Cusack, S. 2002. Large-scale induced fit recognition of an $\mathrm{m}^{7} \mathrm{GpppG}$ cap analog by the human nuclear cap binding complex. EMBO J. 21: 5548-5557.

Morino, S., Hazama, H., Ozaki, M., Teraoma, Y., Shibata, S., Doi, M., Ueda, H., Ishida, T., and Uesugi, S. 1996. Analysis of the mRNA cap-binding ability of human eukaryotic initiation factor- $4 \mathrm{E}$ by use of recombinant wild-type and mutant forms. Eur. J. Biochem. 23: $597-601$.

Niedzwiecka, A., Marcotrigiano, J., Stepinski, J., Jankowska-Anyszka, M., Wyslouch-Cieszynska, A., Dadlez, M., Gingras, A.C., Mak, P., Darzynkiewicz, E., Sonenberg, N., et al. 2002. Biophysical studies of eIF4E cap-binding protein: Recognition of mRNA 5' cap structure and synthetic fragments of eIF4G and 4E-BP proteins. J. Mol. Biol. 319: 615-635.

Pestova, T.V., Lorch, J.R., and Hellen, C.U.T. 2007. The mechanism of translation initiation in eukaryotes. In Translation control in biology and medicine (eds. M.B. Mathews et al.), pp. 87-128. Cold Spring Laboratory Press, New York, NY.

Quiocho, F.A., Hu, G., and Gershon, P.D. 2000. Structural basis of mRNA cap recognition by proteins. Curr. Opin. Struct. Biol. 10: $78-86$.

Raught, B., Gingras, A.C., and Sonenberg, N. 2000. Regulation of ribosomal recruitment in eukaryotes. In Translation control of gene expression (eds. N. Sonenberg et al.), pp. 245-293. Cold Spring Laboratory Press, New York, NY.

Rom, E., Kim, H.C., Gingras, A.C., Marcotrigiano, J., Favre, D., Olsen, H., Burley, S.K., and Sonenberg, N. 1998. Cloning and characterization of 4EHP, a novel mammalian eIF4E-related cap-binding protein. J. Biol. Chem. 273: 13104-13109.
Ruud, K.A., Kuhlow, C., Goss, D.J., and Browning, K.S. 1998. Identification and characterization of a novel cap-binding protein from Arabidopsis thaliana. J. Biol. Chem. 273: 10325-10330.

Tee, A.R., Tee, J.A., and Blenis, J. 2004. Characterizing the interaction of the mammalian eIF4E-related protein 4EHP with 4E-BP1. FEBS Lett. 564: 58-62.

Thompson, J.D., Higgins, D.G., and Gibson, T.J. 1994. CLUSTAL W: Improving the sensitivity of progressive multiple sequence alignment through sequence weighting, position-specific gap penalties, and weight matrix choice. Nucleic Acids Res. 22: 4673-4680.

Tomoo, K., Shen, X., Okabe, K., Nozoe, Y., Fukuhara, S., Morino, S., Sasaki, M., Taniguchi, T., Miyagawa, H., Kitamura, K., et al. 2003. Structural features of human initiation factor $4 \mathrm{E}$, studied by X-ray crystal analyses and molecular dynamics simulations. J. Mol. Biol. 328: $365-383$.

Wilhelm, J.E., Hilton, M., Amos, Q., and Henzel, W.J. 2003. Cup is an eIF4E binding protein required for both the translational repression of oskar and the recruitment of Barentsz. J. Cell Biol. 163: $1197-1204$.

Worch, R., Niedzwiecka, A., Stepinski, J., Mazza, C., JankowskaAnyszka, M., Darzynkiewicz, E., Cusack, S., and Stolarski, R. 2005. Specificity of recognition of mRNA $5^{\prime}$ cap by human nuclear capbinding complex. RNA 11: 1355-1363.

Yoffe, Y., Zuberek, J., Lerer, A., Lewdorowicz, M., Stepinski, J., Altmann, M., Darzynkiewicz, E., and Shapira, M. 2006. Binding specificities and potential roles of isoforms of eukaryotic initiation factor 4E in Leishmania. Eukaryot. Cell 5: 1969-1979.

Zuberek, J., Jemielity, J., Jablonowska, A., Stepinski, J., Dadlez, M., Stolarski, R., and Darzynkiewicz, E. 2004. Influence of electric charge variation at residues 209 and 159 on the interaction of eIF4E with the mRNA 5' terminus. Biochemistry 43: 5370-5379. 

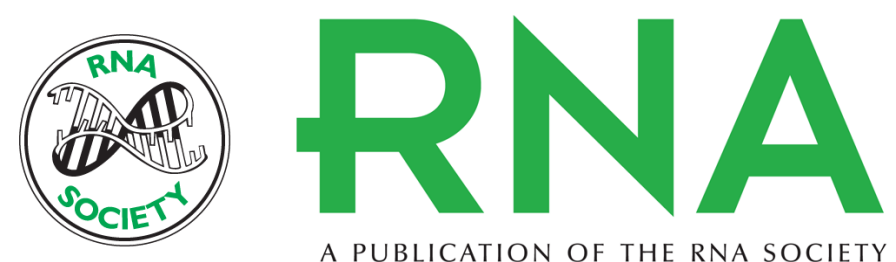

A PUBLICATION OF THE RNA SOCIETY

\section{Weak binding affinity of human 4EHP for mRNA cap analogs}

Joanna Zuberek, Dorota Kubacka, Agnieszka Jablonowska, et al.

RNA 2007 13: 691-697 originally published online March 16, 2007

Access the most recent version at doi:10.1261/rna.453107

\section{References This article cites 32 articles, 11 of which can be accessed free at: http://rnajournal.cshlp.org/content/13/5/691.full.html\#ref-list-1}

\section{License}

Email Alerting Receive free email alerts when new articles cite this article - sign up in the box at the Service top right corner of the article or click here.

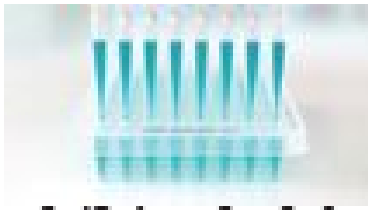

